\title{
Predictive factor for bone cement implantation syndrome in osteoporotic femoral neck fracture undergoing cemented hip arthroplasty: a retrospective review of 142 cases
}

Kulapat Chulsomlee

Mahidol University Faculty of Medicine Ramathibodi Hospital

\section{Sasichol Prukviwat}

Mahidol University Faculty of Medicine Ramathibodi Hospital

Noratep Kulachote

Mahidol University Faculty of Medicine Ramathibodi Hospital

Norachart Sirisreetreeux

Mahidol University Faculty of Medicine Ramathibodi Hospital

Sorawut Thamyongkit

Mahidol University Faculty of Medicine Ramathibodi Hospital

Panithan Tuntiyatorn

Mahidol University Faculty of Medicine Ramathibodi Hospital

Satetha Vasaruchapong

Mahidol University Faculty of Medicine Ramathibodi Hospital

Paphon Sa-ngasoongsong ( $\triangle$ paphonortho@gmail.com )

Mahidol University Faculty of Medicine Ramathibodi Hospital https://orcid.org/0000-0003-1936-4456

Research article

Keywords: bone cement implantation syndrome, cemented hip arthroplasty, femoral neck fracture, femoral stem, osteoporosis, perioperative complication

Posted Date: January 23rd, 2020

DOI: https://doi.org/10.21203/rs.2.21722/v1

License: (c) (1) This work is licensed under a Creative Commons Attribution 4.0 International License.

Read Full License 


\section{Abstract}

Background Bone cement implantation syndrome (BCIS) is a serious and potentially fatal complication in cemented hip arthroplasty (CHA). Although previous studies have identified patients at risk for BCIS, few studies have reported on the association between BCIS and perioperative surgical factors in patients with osteoporotic femoral neck fracture (OFNF) undergoing CHA. This study aimed to identify the prevalence of BCIS and its related outcomes, correlating between BCIS and perioperative surgical factors in these patients. Materials and methods A single-centred, retrospective study was conducted between 2015 and 2018 with patients who sustained OFNF and underwent CHA. Perioperative data and BCIS-related outcomes were reviewed using electronic database and telephone interview. BCIS grading was classified according to the Donaldson classification. All patients were allocated into 2 groups: Group A (BCIS grade 0 or 1: BCIS-gr0/1) and Group B (BCIS grade 2 or 3: BCIS-gr2/3). Multiple logistic regression analysis was used to identify predictive factors for BCIS-gr2/3. Results A total of 142 OFNF patients were included. The prevalence of BCIS-gr2/3 was $6.4 \%(n=9)$. Group B showed a significantly higher major complication rate than Group A (44.4\% vs. 8.3\%, respectively, $\mathrm{p}<0.01)$. The in-hospital and 1-year mortality rates in Group B were also higher than in Group A, but non-significantly different ( $p=0.12$ and $p=0.32$, respectively). Multivariate analysis showed that preinjury non-ambulatory status (odds ratio [OR] 11.83; 95\% confidence interval $[\mathrm{Cl}], 1.06-131.8, \mathrm{p}=0.04)$, arrhythmia (OR 5.65; 95\% Cl, 1.13-28.93, $\mathrm{p}=0.04$ ) and shape-closed femoral stem type (OR 9.78; $95 \% \mathrm{Cl}, 1.65-57.80, \mathrm{p}=0.01)$ were the significant independent predictors for $\mathrm{BCIS-gr2/3}$ in these patients. Conclusion BCIS in OFNF patients undergoing $\mathrm{CHA}$ is common and associates with a high major perioperative complication rate. The patients at risk for BCIS-gr2/3 are those with poor preinjury ambulatory status, those with an underlying cardiac arrhythmia, and those whose $\mathrm{CHA}$ procedures use a shape-closed femoral stem design.

\section{Background}

Bone cement implantation syndrome (BCIS) is a severe and life-threatening perioperative complication which is an important cause of perioperative morbidity and mortality in elderly patients undergoing cemented hip arthroplasty (CHA). The incidence of BCIS ranges from 17-28\% [1, 2] with an intraoperative mortality rate of $1.6 \%$, depending on type of fracture, and could be as high as $4.3 \%$ in metastatic hip fracture [3]. Although the exact pathophysiology of BCIS is still poorly understood, recent studies showed that the most likely possible mechanism related to the embolization results from high intramedullary pressures during cementation and prosthesis insertion [4]. This syndrome is characterised by hypoxemia, hypotension, increased pulmonary vascular pressure, cardiac arrhythmia and sudden cardiac arrest [5-8]. According to previous studies, numerous risk factors for BCIS development-including old age, osteoporosis, concomitant hip fracture, pre-existing cardiovascular or pulmonary compromise, warfarin or diuretics use, American Society of Anesthesiologists (ASA) grades of 3 and 4, and use of long-stemmed femoral component-have been identified $[1,9]$.

Despite the very high risk for BCIS, the use of bone cement in hip replacement surgery is still necessary to establish a well-fixed prosthesis in the patients with poor bone quality, such as those with osteoporotic 
femoral neck fracture (OFNF). Therefore, to prevent BCIS during CHA for hip fracture, several recommendations-including thoroughly washing and drying the femoral canal before cement implantation, applying cement in retrograde fashion using a cement gun with a suction catheter and an intramedullary plug in the femoral shaft, and avoiding excessive pressurization-have been proposed [10]. However, these recommendations did not include the femoral stem option that varies from a small taper-shaped (or "force-closed" type) to a large wedge-shaped (or "shape-closed" type) design.

Theoretically, the large wedge-shaped stem design should create higher intramedullary pressure and greater emboli formation during prosthesis insertion, resulting in higher risk for BCIS than with the small taper-shaped femoral stem design. Moreover, to the best of our knowledge, only one study has addressed the risk factors for $\mathrm{BCIS}$ in patients with OFNF undergoing $\mathrm{CHA}$ [2]. However, the previous study did not include some important surgical-related factors, such as time to surgery, operative time, type of operation, femoral stem type and intraoperative blood loss.

Therefore, the aim of the current study was to investigate the prevalence of BCIS in patents with OFNF undergoing $\mathrm{CHA}$, its impact on patient outcomes, and the correlation between $\mathrm{BCIS}$ and perioperative surgical factors, including femoral stem type.

\section{Methods}

\section{Study design, participants, and inclusion and exclusion criteria}

The present study is a single-centred retrospective review that was approved by the Institutional Board Review (Protocol number ID 05-61-57). Hip fracture patients who underwent CHA during a 4-year period (between January 2015 and December 2018) were identified and reviewed from the hospital electronic records. The inclusion criteria were patients who had 1) sustained low energy trauma and been diagnosed with OFNF and 2) underwent cemented hip replacement. The exclusion criteria were patients who had 1) multiple fractures or poly traumatized injury, 2) revision surgery and 3) pathological fracture other than osteoporosis hip fracture, such as metastatic fracture.

\section{Perioperative protocol, surgical procedure and implant selection}

All patients had received the same preoperative protocol with routine deep vein thrombosis (DVT) screening with doppler ultrasonography. In cases where patients had unexplainable dyspnoea with hypoxemia that was clinically suspicious for pulmonary embolism (PE), computer tomography angiography (CTA) was performed. The anaesthetic technique, either general or regional anaesthesia, was based on the decision of the respective anaesthesiologists. The surgical approach was an anterolateral approach with anterior hemimyotomy of the gluteus medius, in the lateral decubitus position. The type of operation, either cemented bipolar hip arthroplasty (BHA) or hybrid total hip replacement (THA), and the type of femoral stem were selected according to the respective surgeons' 
preferences. For THA, the patients all received cementless acetabulum cup combined with cemented femoral stem. The cemented femoral stem choices in our institution included cemented Corail stem (DePuy International, Leeds, UK), C-stem (DePuy International, Leeds, UK), CPT stem (Zimmer Biomet, Warsaw, IN) and Exeter stem (Stryker Howmedica Osteonics, Mahwah, NJ). All polymethylmethacrylate (PMMA) bone cement used in this study was high-viscosity PALACOS $\rightarrow$ bone cement (Heraeus Medical LLC, Yardley, PA). Our routine cementing technique was done in the following steps: 1) inform the anaesthesiologist for the cementation during the brushing and drying of the femoral canal, 2) manually mix the cement according to the manufacturer's instruction, 3 ) insert an intramedullary cement restrictor plug $2 \mathrm{~cm}$ below the tip of the femoral stem, 4) use the distal suction catheter on the top of the intramedullary plug and pull the catheter out as soon as it is blocked with cement, 5) insert cement with finger-packed technique, at 2 minutes after cement mixing, without proximal pressurization, and 6) insert femoral stem with distal centralizer (except for the cemented Corail stem which did not require distal centralizer) and wait for the hardening of cement.

\section{Data collection and outcome measurement}

The charts were reviewed, using the electronic hospital database, to obtain the required data, including demographic data, perioperative data and postoperative data. The following demographic data were collected: age, gender, body mass index (BMI), ASA physical status [11], comorbid disease, preinjury ambulatory status, anti-platelet and anti-coagulant medication use, and preoperative laboratory values, such as haemoglobin $(\mathrm{Hb})$ level, platelet count, glomerular infiltration rate (GFR) and albumin level. Preinjury ambulatory status was classified into 3 groups: ambulatory, ambulatory with assistance and non-ambulatory. Ambulatory was defined as independent ambulation. Ambulatory with assistance was defined as requiring assistance, such as with a cane or walker, for ambulation. Non-ambulatory was defined as a composite of wheelchair and bedridden status [12].

Perioperative data-including type of anaesthesia, operative time, estimated blood loss, intraoperative findings related to BCIS and BCIS grading, and packed red cell (PRC) transfusion-were reviewed and recorded by one author (SP), an anaesthesiologist who was not involved in the data analysis. BCIS was defined as sudden hypoxia, hypotension, cardiac arrhythmia and sudden cardiac arrest at the time of the cement insertion. BCIS grading was classified according to the classification system proposed by Donaldson [1] (Table 1). Each patient was classified as having no BCIS (grade 0), or BCIS grade 1, 2 or 3, depending on the severity of hypotension, oxygen desaturation, degree of consciousness and cardiovascular collapse status. Femoral stem was classified in 2 types according to the classification proposed by Shen [13]: shape-closed type (large stem geometry that fully occupies the medullary canal) and forced-closed type (small taper design that allows the subsidence of the femoral stem in the cement mantle). Therefore, in our study, the cemented Corail stem was classified as shape-closed type, while the C-stem, CPT stem and Exeter stem were all classified as force-closed type. 
Table 1

BCIS classification system proposed by Donaldson [1]

\section{Grade Description}

Grade No BCIS

0

Grade Moderate hypoxia (O2 Sat. $<94 \%$ ) or hypotension (fall in SBP $>20 \%$ )

1

Grade Severe hypoxia (02 Sat. $<88 \%$ ) or hypotension (fall in SBP $>40 \%$ ) or unexpected loss of 2 consciousness

Grade Cardiovascular collapse requiring CPR

3

BCIS: bone cement implantation syndrome, 02 Sat.: oxygen concentration, SBP: systolic blood pressure, CPR: cardiopulmonary resuscitation

Postoperative data-including major perioperative complications, in-hospital death during admission, and death due to hip fracture-related complication within 1 year postoperatively-were collected via chart review and telephone interview. The major perioperative complications were defined as follows: 1) cardiac complication requiring inotropic drug and admittance into coronary care unit, 2) pulmonary complication requiring ventilator support, 3) renal complication requiring peritoneal or haemodialysis, 4) infection requiring intravenous antibiotic treatment, and 5) symptomatic thromboembolic complication (acute stroke, symptomatic DVT or symptomatic pulmonary embolism).

\section{Statistical analysis}

MedCalc software version 15.8 was used to analyse the data. Normally distributed continuous data were presented as mean and standard deviation and compared with Student t-test, while non-normally distributed continuous data were presented as median and interquartile range. Categorical data were presented as proportion of cases and compared with Fisher's exact test or Chi-square test as appropriate. All patients were allocated into 2 groups based on BCIS grading: Group A (BCIS grade 0 or 1: BCIS-Gr0/1) and Group B (BCIS grade 2 or 3: BCIS-Gr2/3). Risk factors for BCIS-Gr2/3 were compared between both groups. Univariate logistic regression analysis was used to evaluate the association between risk factors and $\mathrm{BCIS}-\mathrm{Gr} 2 / 3$, and the predictive factors with values of $\mathrm{p} \leq 0.10$ were calculated by multivariate logistic regression analysis. Significance was defined as values of $p<0.05$.

\section{Results}

\section{General characteristic data of study population}

Between January 2015 and December 2018, 156 patients who were diagnosed with OFNF and underwent CHA were recruited into the present study. Fourteen patients were excluded due to multiple fracture $(n=1)$, revision surgery $(n=4)$ and metastatic fracture $(n=9)$. Therefore, a total of 142 patients were included in 
this study. Among those patients, the median age was 80.5 years (range 34-98 years), and 120 of them $(84.5 \%)$ were female. Thirty-three patients $(23.4 \%)$ were classified as ASA grade 4 , and 70 patients $(49.3 \%)$ were taking either anti-platelet or anti-coagulation medication prior to hospitalization. The median time from injury to surgery was 4 days (range 1-180 days). BHA was used in 134 patients (94.4\%), while 8 patients (5.6\%) received THA. The force-closed type femoral stem was used in 94 patients $(66.2 \%)$, while 48 of them (33.8\%) received shape-closed type femoral stems. Regional anaesthesia was used in 114 patients $(80.3 \%)$, whereas general anaesthesia was given to 28 patients (19.7\%). The median operative time was 165 minutes (range 105-270 minutes). The median estimated blood loss was $300 \mathrm{~mL}$ (range 50-1650 mL), and the median total PRC transfusion was 1 unit (range 07 units).

\section{Incidence of $\mathrm{BCIS}$, perioperative complications and mortality rate}

The incidence rates of BCIS grades $0,1,2$ and 3 were $73.9 \%(n=105), 19.7 \%(n=28), 3.6 \%(n=5)$ and $2.8 \%(n=4)$, respectively. Table 2 shows the information from 9 patients who had BCIS grade 2 or 3 . The demographic data and perioperative data with simple statistical comparison between those who had BCIS-gr0/1 (Group A, $n=133$ ) and those who had BCIS-gr2/3 (Group B, $n=9$ ) are shown in Table 3. There was no significant difference in the demographic data for age; gender; BMl; ASA classification grade 4; pre-existing ischemic heart disease or congestive heart failure, renal failure, chronic obstructive pulmonary disease, stroke, cancer, and dementia; concomitant anti-platelet or anti-coagulant medications; preoperative laboratory values; type of anaesthesia; anaesthetic time; and type of operation between groups ( $p>0.05$ ). However, compared to Group A, Group B had significantly higher incidences of preexisting cardiac arrhythmia, preinjury ambulatory status and shape-closed femoral stem type $(p<0.05$ all). 
Table 2

Information related to perioperative findings in 9 patients who had BCIS grades 2 and 3

\begin{tabular}{|c|c|c|c|c|}
\hline $\begin{array}{l}\text { Patient } \\
\text { no. }\end{array}$ & $\begin{array}{l}\text { BCIS } \\
\text { grading }\end{array}$ & $\begin{array}{l}\text { Preoperative } \\
\text { DVT } \\
\text { screening }\end{array}$ & $\begin{array}{l}\text { Intraoperative } \\
\text { findings after } \\
\text { cementation }\end{array}$ & Major postoperative complications \\
\hline 1 & 3 & Negative & Atrial fibrillation & $\begin{array}{l}\text { Acute } \mathrm{Ml} \text {, then cardiac arrest } 72 \text { hours } \\
\text { postop and death }\end{array}$ \\
\hline 2 & 2 & Negative & $\begin{array}{l}40 \% \text { drop in } \\
\text { systolic blood } \\
\text { pressure }\end{array}$ & - \\
\hline 3 & 3 & Negative & $\begin{array}{l}40 \% \text { drop in } \\
\text { systolic blood } \\
\text { pressure }\end{array}$ & $\begin{array}{l}\text { Acute } \mathrm{Ml} \text {, cardiac arrest at } 12 \text { hours } \\
\text { postop, acute cholangitis, and acute renal } \\
\text { failure }\end{array}$ \\
\hline 4 & 3 & Negative & $\begin{array}{l}\text { Intraoperative } \\
\text { cardiac arrest }\end{array}$ & - \\
\hline 5 & 2 & Negative & $\begin{array}{l}>40 \% \text { drop in } \\
\text { systolic blood } \\
\text { pressure, }\end{array}$ & $\begin{array}{l}\text { Acute right-sided heart failure requiring } \\
\text { inotrope and } \mathrm{PCl}\end{array}$ \\
\hline 6 & 3 & Negative & $\begin{array}{l}>40 \% \text { drop in } \\
\text { systolic blood } \\
\text { pressure }\end{array}$ & $\begin{array}{l}\text { Cardiac arrest at } 24 \text { hours } \\
\text { postoperatively but ROSC }\end{array}$ \\
\hline 7 & 2 & Negative & $\begin{array}{l}\text { O2 Sat. drop from } \\
99-85 \%\end{array}$ & - \\
\hline 8 & 2 & Negative & $\begin{array}{l}40 \% \text { drop in } \\
\text { systolic blood } \\
\text { pressure }\end{array}$ & - \\
\hline 9 & 2 & Negative & $\begin{array}{l}40 \% \text { drop in } \\
\text { systolic blood } \\
\text { pressure }\end{array}$ & - \\
\hline $\begin{array}{l}\text { BCIS: bc } \\
\text { PCl: per } \\
\text { O2 Sat.: }\end{array}$ & $\begin{array}{l}\text { cement } \\
\text { aneous }\end{array}$ & $\begin{array}{l}\text { plantation sy } \\
\text { onary interve }\end{array}$ & $\begin{array}{l}\text { Irome, DVT: deep ve } \\
\text { on } \\
\text { urn of spontaneous }\end{array}$ & $\begin{array}{l}\text { thrombosis, Ml: myocardial infarction, } \\
\text { culation }\end{array}$ \\
\hline
\end{tabular}


Table 3

Demographic data in 142 patients who underwent cemented hip arthroplasty with statistical comparison between those who had BCIS grades $0-1$ (Group A) and BCIS grades 2-3 (Group B)

\begin{tabular}{|c|c|c|c|c|}
\hline & Total $(n=142)$ & $\begin{array}{l}\text { Group A }(n= \\
133)\end{array}$ & Group B $(n=9)$ & $\begin{array}{l}\mathrm{p}- \\
\text { value }\end{array}$ \\
\hline Age, year \# $\rrbracket$ & $80.5(72-85)$ & $80(75-84)$ & $83 \pm 11$ & 0.23 \\
\hline Female gender $\mathbb{\Delta}$ & $120(84.5)$ & $112(84.3)$ & 8 (88.9) & 1.00 \\
\hline BMI, $\mathrm{kg} / \mathrm{m}^{2} \otimes$ & $21.4 \pm 3.6$ & $21.3 \pm 3.6$ & $22.2 \pm 3.8$ & 0.71 \\
\hline ASA grade 4 \ & $33(23.4)$ & $30(22.5)$ & $3(33.3)$ & 0.43 \\
\hline \multicolumn{5}{|l|}{ Comorbid diseases $\mathbb{Q}$} \\
\hline IHD & $23(16.2)$ & $21(15.7)$ & $2(22.2)$ & 0.63 \\
\hline CHF & $8(5.6)$ & $7(5.3)$ & $1(11.1)$ & 0.42 \\
\hline Cardiac arrhythmia & $20(14.1)$ & $16(12)$ & $4(44.4)$ & 0.02 \\
\hline COPD & $7(4.9)$ & $7(5.3)$ & $0(0)$ & 1.00 \\
\hline Stroke & $5(3.5)$ & $4(3)$ & $1(11.1)$ & 0.28 \\
\hline Cancer & $23(16.2)$ & $23(17.3)$ & $0(0)$ & 0.35 \\
\hline Cognitive impairment & $19(13.4)$ & $17(12.8)$ & $2(22.2)$ & 0.34 \\
\hline Renal failure & $40(28.2)$ & $38(28.6)$ & $2(22.2)$ & 1.00 \\
\hline \multicolumn{5}{|c|}{ Preinjury ambulatory status $\Delta$} \\
\hline Am:Amb-Ass:Non-Amb & $91: 46: 5$ & $86: 44: 3$ & $5: 2: 2$ & 0.01 \\
\hline 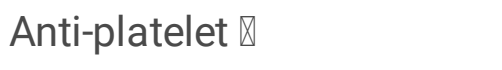 & $50(35.2)$ & $46(34.5)$ & $4(44.4)$ & 0.72 \\
\hline Anti-coagulant $\mathbb{Z}$ & $20(14.1)$ & $17(12.8)$ & $3(33.3)$ & 0.12 \\
\hline \multicolumn{5}{|c|}{$\begin{array}{l}\text { Preoperative laboratory value } \\
\# \square\end{array}$} \\
\hline Haemoglobin, g/dl & $11.3 \pm 1.5$ & $11.3 \pm 1.5$ & $11.7 \pm 1.6$ & 0.49 \\
\hline Platelet, x103/mm3 & $230(182-313)$ & $231(186-309)$ & $233 \pm 86$ & 0.57 \\
\hline Lymphocyte count, / $\mathrm{mm}^{3}$ & $\begin{array}{l}1035(764- \\
1337)\end{array}$ & $\begin{array}{l}1031(787- \\
1467)\end{array}$ & $1122 \pm 432$ & 0.46 \\
\hline GFR, mL/minute/1.73 $\mathrm{m}^{2}$ & $70.2(35-84)$ & $70.2(34.5-84.2)$ & $60.2 \pm 21.9$ & 0.90 \\
\hline Albumin, g/dl & $\begin{array}{l}32.6(28.0- \\
35.8)\end{array}$ & $32.4(28.6-36.0)$ & $30.7 \pm 4.5$ & 0.55 \\
\hline
\end{tabular}




\begin{tabular}{|c|c|c|c|c|}
\hline & Total $(n=142)$ & $\begin{array}{l}\text { Group A }(n= \\
133)\end{array}$ & Group B $(n=9)$ & $\begin{array}{l}\mathrm{p}- \\
\text { value }\end{array}$ \\
\hline INR & $1.03(0.98-1.09)$ & $1.03(0.98-1.08)$ & $\begin{array}{l}1.03(0.99- \\
1.11)\end{array}$ & 0.97 \\
\hline Time to surgery, day \# & $4(2-12)$ & $4(2-12)$ & $6(2-23)$ & 0.38 \\
\hline Anaesthesia GA: RA $\Delta$ & 28:114 & 27:106 & $1: 8$ & 0.69 \\
\hline Operation THA: BHA $\Delta$ & $8: 134$ & $7: 126$ & $1: 8$ & 0.42 \\
\hline \multicolumn{5}{|l|}{ Femoral stem type $\Delta$} \\
\hline Shape-closed:Force-closed & 48:94 & $41: 92$ & 7:2 & $<0.01$ \\
\hline Operative time, $\min \# \square$ & $165(145-191)$ & $165(150-191)$ & $149 \pm 32$ & 0.09 \\
\hline Estimated blood loss, ml \# & $300(200-500)$ & $300(200-500)$ & $350(233-450)$ & 0.58 \\
\hline Total PRC transfusion, unit \# & $1(0-2)$ & $1(0-2)$ & $1(0-2)$ & 0.39 \\
\hline \multicolumn{5}{|c|}{ 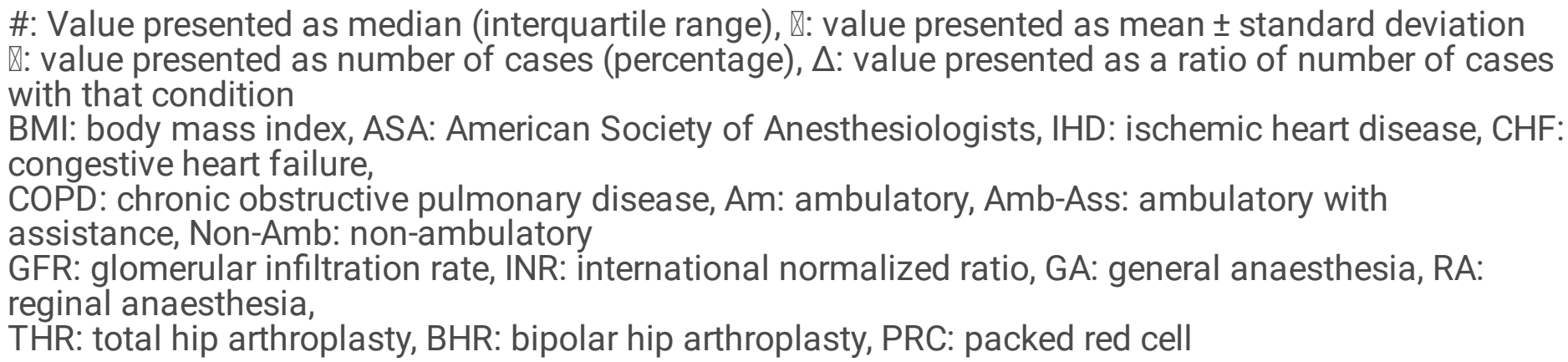 } \\
\hline
\end{tabular}

Table 4 shows the in-hospital and 1-year postoperative mortality and major perioperative complications during admission. Postoperatively, two patients in each group died within the admission period. One patient $(0.8 \%)$ in Group A died from respiratory failure at 4 weeks after the operation, and one patient (11.1\%) in Group B died from cardiovascular failure 3 days after the operation. After discharge, four patients in Group A (3.8\%) died from respiratory infection, acute myocardial infarction, acute stroke and gastrointestinal bleeding, respectively. None of the patients in Group B died after hospital discharge. The overall 1-year mortality rate was $4.2 \%(n=6)$, and the major perioperative complication rate was $10.6 \%$ ( $n$ $=15$ ). There was a statistically significant higher rate of major perioperative complications in Group $B$ compared to Group A ( $44.4 \%$ vs. $8.3 \%, \mathrm{p}<0.01)$. Group B also had non-significantly higher in-hospital and 1 -year mortality rates than Group $A(11.1 \%$ vs. $0.8 \%, p=0.12$ and $11.1 \%$ vs. $3.8 \%, p=0.32$, respectively). 
Table 4

In-hospital, 1-year postoperative mortality and perioperative complication

\begin{tabular}{|c|c|c|c|}
\hline & Group A & Group B & p-value \\
\hline \multicolumn{4}{|l|}{ Mortality 『 } \\
\hline In-hospital & $1(0.8)$ & $1(11.1)$ & 0.12 \\
\hline 1-year & $5(3.8)$ & $1(11.1)$ & 0.32 \\
\hline \multicolumn{4}{|c|}{ Perioperative complications } \\
\hline Cardiovascular & 8 & 4 & \\
\hline Pulmonary & 2 & 0 & \\
\hline Renal & 1 & 1 & \\
\hline Infection & 0 & 1 & \\
\hline Thromboembolism & 0 & 0 & \\
\hline Overall complications $\mathbb{Q}$ & $11(8.3)$ & $4(44.4)$ & $<0.01$ \\
\hline \multicolumn{4}{|c|}{ \: value presented as number of cases (percentage) } \\
\hline
\end{tabular}

\section{Logistic regression analysis of the risk factors for $\mathrm{BCIS}$}

Table 5 demonstrates the univariate and multivariate logistic regression analysis of the risk factors for BCIS-gr2/3. Via univariate analysis, the predictive factors that were associated with BCIS-gr2/3 with $p \leq 0.10$ were the preinjury non-ambulatory status $(p=0.01)$, underlying cardiac arrhythmia $(p=0.01)$, use of anti-coagulation medication ( $p=0.10)$, time to surgery $(p=0.05)$, operative time $(p=0.09)$ and shapeclosed femoral stem $(p=0.01)$. However, multivariate analysis showed that only preinjury non-ambulatory status (odds ratio $[\mathrm{OR}]=11.83 ; 95 \%$ confidence interval $[\mathrm{Cl}], 1.06-131.8, \mathrm{p}=0.04$ ), cardiac arrhythmia (OR $=5.65 ; 95 \% \mathrm{Cl}, 1.13-28.93, \mathrm{p}=0.04)$ and shape-closed femoral stem $(\mathrm{OR}=9.78 ; 95 \% \mathrm{Cl}, 1.65-57.80, \mathrm{p}=$ 0.01 ) were significant independent predictors for BCIS-gr $2 / 3$. The area under the curve (AUC) of this prediction model was $0.85(95 \% \mathrm{Cl}, 0.78-0.90)$. 
Table 5

Univariate and multivariate logistic regression analyses for risk factors of BCIS grades 2 and 3

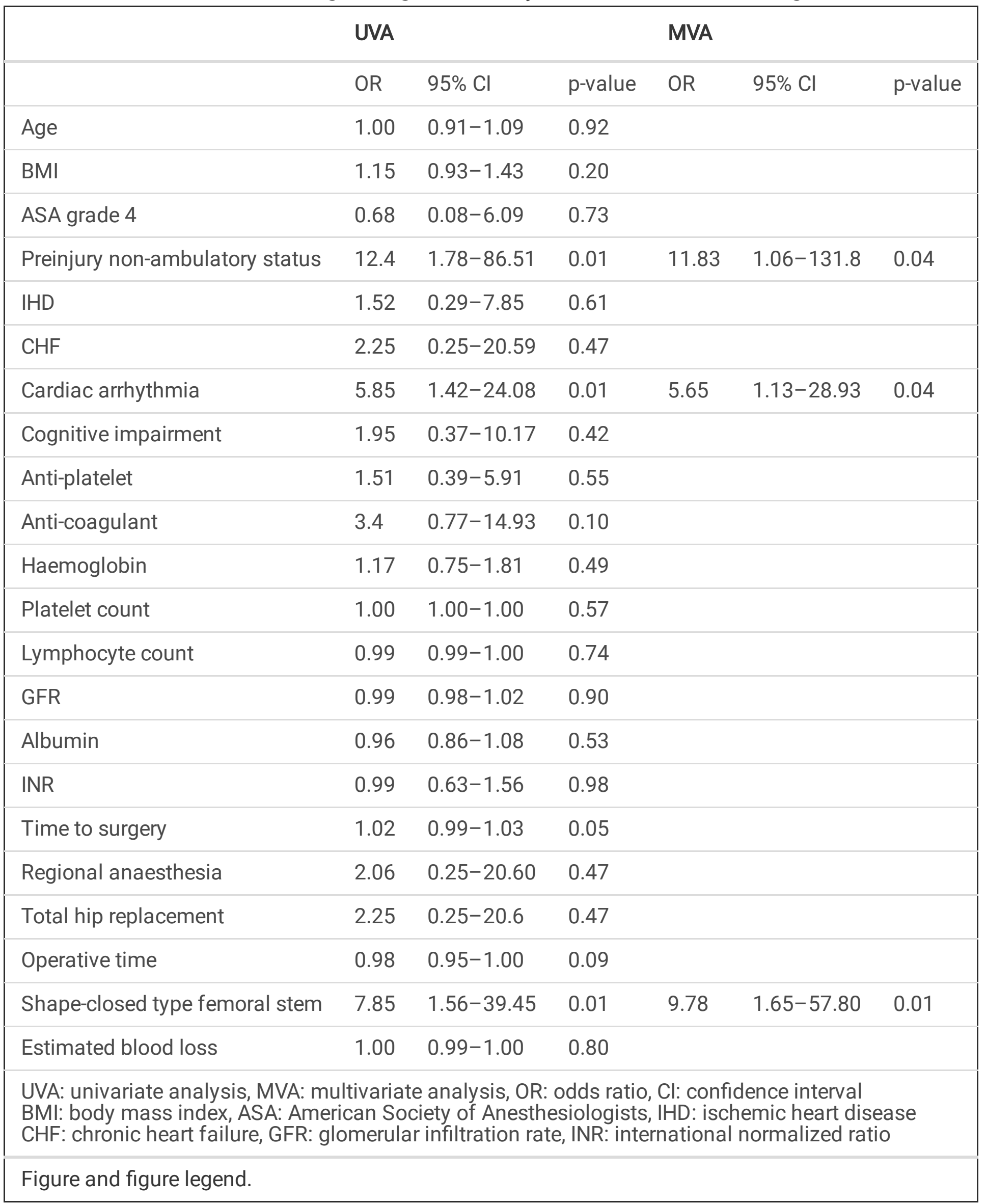




\section{Discussion}

$\mathrm{BCIS}$ is a serious and potentially lethal perioperative complication of cemented hip replacement which is theoretically caused by cement monomer mediation, immune reaction or emboli during cement and prosthesis insertion. The aim of this study was to analyse the incidence and outcome of BCIS in OFNF patients undergoing cemented hip replacement, and to investigate the predictive factor for BCIS in these patients.

The incidence of overall BCIS in the present study was 26.1\% (with BCIS grades 1, 2 and 3 as $19.7 \%, 3.6 \%$ and $2.8 \%$, respectively), which is comparable with previous studies $[2,14]$. The in-hospital and postoperative 1-year mortality rates in patients with BCIS-gr2/3 were higher than those in patients with BCIS-gr0/1 ( $11.1 \%$ vs. $0.8 \%$, and $11.1 \%$ vs. $3.8 \%$, respectively), but did not have statistical significance. Although these results were dissimilar to the previous study by Olsen et al. [2] that reported significantly higher 30-day and 1-year mortality in BCIS-gr2/3 compared with BCIS-gro/1, this difference could be explained by the relatively small study population in the present study. Moreover, our results also showed that major postoperative complications in patients with BCIS-gr2/3 were also significantly higher than those in patients with BCIS-gr0/1 (44.4\% vs. $8.3 \%, \mathrm{p}<0.01)$. These results highlight the significance problem of this complication and emphasise the need for meticulous attention to preoperative and intraoperative management.

This study also revealed the significant correlation between BCIS-gr2/3 and the patient and surgical factors. From the multivariate regression analysis, our study showed that the independent factors for BCIS-gr2/3 were preinjury wheelchair or bedridden ambulatory status $(\mathrm{OR}=11.8,95 \% \mathrm{Cl} 1.1-131.8, \mathrm{p}=$ $0.04)$, underlying cardiac arrhythmia $(O R=5.7,95 \% \mathrm{Cl} 1.1-28.9, \mathrm{p}=0.04)$ and use of shape-closed femoral stem $(\mathrm{OR}=9.8,95 \% \mathrm{Cl} 1.7-57.8, \mathrm{p}=0.01)$. The poor preinjury ambulatory status and cardiac arrhythmia are both directly related to the patients' impaired cardio-pulmonary function and, therefore, result in significant physiological disturbance during surgery and cement implantation. This finding is also comparable to the previous studies that showed the significant association between BCIS-gr2/3 and patients' physiological factors, such as ASA physical status grade 3 or 4 , underlying chronic obstructive pulmonary disease [2] and pulmonary hypertension [15].

The significant correlation between shape-closed femoral stem and BCIS-gr2/3 could be explained by the pressure-model mechanism as an effect of stem geometry. Generally, the shape-closed stem has larger proximal geometry than a force-closed stem, which would result in higher intramedullary pressure during stem insertion and release a greater number of embolic particles into the vascular system. Consequently, the shape-closed stem insertion should pose a higher risk of BCIS-gr2/3 than the force-closed stem.

The strengths of the present study are related to the preoperative DVT screening to exclude preoperative DVT in all cases and the use of the same surgical approach and cementation protocol in the treatment of osteoporotic femoral neck fracture in the elderly, as previously described. Therefore, some confounding factors-such as the type of bone cement used, the time of cement insertion and the cementing technique -could be controlled. Moreover, to the best of our knowledge, the present study is the first study that 
demonstrates the impact of femoral geometry on the severity of BCIS. Hence, more studies on how the shape-closed femoral stem affects intramedullary pressure are required.

This study had the following limitations. First, regarding the retrospective nature of this study, some useful clinical information, such as smoking status and alcohol intake, was not available in all cases and, therefore, was absent from our analysis. Second, our sample size was relatively small and from only one centre. Thus, other possible risk factors-such as medications, anaesthetic technique and type of surgery -might remain undetected. Finally, the cementing technique used in our institution (use of high viscosity cement with manual mixing and finger-packed technique) did not comply with the previous recommendation (use of low viscosity cement with vacuum mixing and cement gun) [10], mainly due to the restriction of medical insurance in our country. This cementing technique protocol might affect the outcome of the present study. However, our results did not show a higher incidence of BCIS, perioperative complications or postoperative mortality compared with previous studies. Therefore, a well-designed multicentred prospective study with a larger sample size is recommended to explore the effect of other potential risk factors.

\section{Conclusion}

BCIS in OFNF patients undergoing CHA is common and associated with high morbidity and mortality rates. The results of this study showed that preinjury wheelchair or bedridden ambulatory status, underlying cardiac arrhythmia and the use of shape-closed femoral stem were significant independent factors for high-grade BCIS. To avoid BCIS, complete preoperative assessment and perioperative management are required. Patients with high risk of BCIS must be identified and individually managed following suitable guidelines for risk reduction. If possible, the shape-closed femoral stem should be avoided.

\section{Abbreviations}

BCIS: $\quad$ Bone cement implantation syndrome

CHA: $\quad$ cemented hip arthroplasty

OFNF: $\quad$ osteoporotic femoral neck fracture

BCIS-gr0/1: BCIS grade 0 or 1

BCIS-gr2/3: BCIS grade 2 or 3

OR: $\quad$ odds ratio

Cl: $\quad$ confidence interval

ASA: $\quad$ American Society of Anesthesiologists 


$\begin{array}{ll}\text { DVT: } & \text { deep vein thrombosis } \\ \text { PE: } & \text { pulmonary embolism } \\ \text { CTA: } & \text { computer tomography angiography } \\ \text { BHA: } & \text { bipolar hip arthroplasty } \\ \text { THA: } & \text { total hip replacement } \\ \text { PMMA: } & \text { polymethylmethacrylate } \\ \text { BMI: } & \text { body mass index } \\ \text { Hb: } & \text { haemoglobin } \\ \text { GFR: } & \text { glomerular infiltration rate } \\ \text { PRC: } & \text { packed red cell }\end{array}$

\section{Declarations}

\section{Ethics approval and consent to participate}

This study was reviewed and approved by the Ethical Clearance Committee on Human Rights to Research Including Human Subjects, Faculty of Medicine Ramathibodi Hospital, Mahidol University (Protocol number: ID 05-61-57).

\section{Consent for publication}

According to ethical approval, no informed consent was necessary from individual patients in the retrospective review study since all data were gathered retrospectively from medical records.

\section{Availability of data and material}

Supporting data is available with the corresponding author on request.

\section{Competing interests}

The authors declare that they have no competing interests.

\section{Funding}

No external funding was obtained for this study.

\section{Authors' contributions}


All authors conceptualized and designed the study. KL and SP performed data collection. KL and PS were responsible for analysis and interpretation of data, and draft the manuscript. NK, NS, ST, PT, SV helped to revise the manuscript critically for important intellectual content. All authors read and approved the final manuscript.

\section{Acknowledgements}

The authors would like to thank Department of Orthopedics, Faculty of Medicine Ramathibodi Hospital, Mahidol University for all of the kindly help and permission to carry out the study.

\section{Authors' information}

${ }^{1}$ Chakri Naruebodindra Medical Institute, Faculty of Medicine Ramathibodi Hospital, Mahidol University, Bangkok, Thailand

${ }^{2}$ Department of Orthopedics, Faculty of Medicine Ramathibodi Hospital, Mahidol University, Bangkok, Thailand

\section{References}

1. Donaldson AJ, Thomson HE, Harper NJ, Kenny NW. Bone cement implantation syndrome. BJA: British Journal of Anaesthesia. 2009;102(1):12-22.

2. Olsen F, Kotyra M, Houltz E, Ricksten SE. Bone cement implantation syndrome in cemented hemiarthroplasty for femoral neck fracture: incidence, risk factors, and effect on outcome. $\mathrm{Br} J$ Anaesth. 2014 Nov;113(5):800-6. PubMed PMID: 25031262. Epub 2014/07/18.

3. Parvizi J, Holiday AD, Ereth MH, Lewallen DG. The Frank Stinchfield Award. Sudden death during primary hip arthroplasty. Clin Orthop Relat Res. 1999 Dec(369):39-48. PubMed PMID: 10611859. Epub 1999/12/28.

4. Orsini EC, Byrick RJ, Mullen JB, Kay JC, Waddell JP. Cardiopulmonary function and pulmonary microemboli during arthroplasty using cemented or non-cemented components. The role of intramedullary pressure. JBJS. 1987;69(6).

5. Duncan JA. Intra-operative collapse or death related to the use of acrylic cement in hip surgery. Anaesthesia. 1989 Feb;44(2):149-53. PubMed PMID: 2929940. Epub 1989/02/01.

6. Kallos T. Impaired arterial oxygenation associated with use of bone cement in the femoral shaft. Anesthesiology. 1975 Feb;42(2):210-5. PubMed PMID: 1115374. Epub 1975/02/01.

7. Modig J, Busch C, Olerud S, Saldeen T, Waernbaum G. Arterial hypotension and hypoxaemia during total hip replacement: the importance of thromboplastic products, fat embolism and acrylic monomers. Acta Anaesthesiol Scand. 1975;19(1):28-43. PubMed PMID: 1136690. Epub 1975/01/01.

8. Urban MK, Sheppard R, Gordon MA, Urquhart BL. Right ventricular function during revision total hip arthroplasty. Anesth Analg. 1996 Jun;82(6):1225-9. PubMed PMID: 8638795. Epub 1996/06/01. 
9. Khanna G, Cernovsky J. Bone cement and the implications for anaesthesia. Continuing Education in Anaesthesia Critical Care \& Pain. 2012;12(4):213-6.

10. Membership of Working P, Griffiths R, White SM, Moppett IK, Parker MJ, Chesser TJ, et al. Safety guideline: reducing the risk from cemented hemiarthroplasty for hip fracture 2015: Association of Anaesthetists of Great Britain and Ireland British Orthopaedic Association British Geriatric Society. Anaesthesia. 2015 May;70(5):623-6. PubMed PMID: 25866041. Pubmed Central PMCID: PMC6681143. Epub 2015/04/14.

11. Daabiss M. American Society of Anaesthesiologists physical status classification. Indian J Anaesth. 2011 Mar;55(2):111-5. PubMed PMID: 21712864. Pubmed Central PMCID: PMC3106380. Epub 2011/06/30.

12. Lu K, Farber A, Schermerhorn ML, Patel VI, Kalish JA, Rybin D, et al. The effect of ambulatory status on outcomes of percutaneous vascular interventions and lower extremity bypass for critical limb ischemia in the Vascular Quality Initiative. J Vasc Surg. 2017 Jun;65(6):1706-12. PubMed PMID: 28216361. Epub 2017/02/22.

13. Shen G. Femoral stem fixation. An engineering interpretation of the long-term outcome of Charnley and Exeter stems. J Bone Joint Surg Br. 1998 Sep;80(5):754-6. PubMed PMID: 9768879. Epub 1998/10/13.

14. Rutter PD, Panesar SS, Darzi A, Donaldson LJ. What is the risk of death or severe harm due to bone cement implantation syndrome among patients undergoing hip hemiarthroplasty for fractured neck of femur? A patient safety surveillance study. BMJ Open. 2014 Jun 12;4(6):e004853. PubMed PMID: 24924418. Pubmed Central PMCID: PMC4069865. Epub 2014/06/14.

15. Leidinger W, Hoffmann G, Meierhofer JN, Wolfel R. [Reduction of severe cardiac complications during implantation of cemented total hip endoprostheses in femoral neck fractures]. Unfallchirurg. 2002 Aug;105(8):675-9. PubMed PMID: 12243012. Epub 2002/09/24. Verminderung von schweren kardialen Komplikationen wahrend der Implantation von zementierten Hufttotalendoprothesen bei Oberschenkelhalsfrakturen.

\section{Figures}




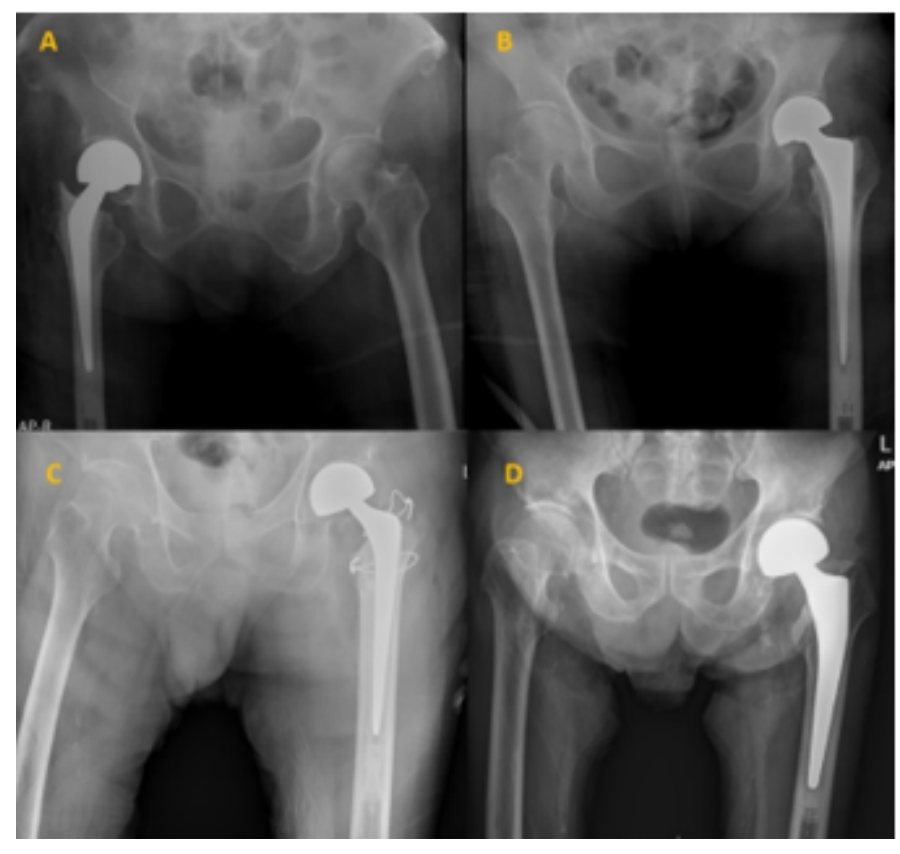

\section{Figure 1}

Cemented femoral stem classification. "Force-closed" types with a small taper-shaped design: (A) C-stem (DePuy International, Leeds), (B) CPT stem (Zimmer Biomet, Warsaw, IN) and (C) Exeter stem (Stryker Howmedica Osteonics, Mahwah, NJ). "Shaped-closed" type with a large wedge-shaped design: (D) cemented Corail stem (DePuy International, Leeds). 